\title{
Improving the prospects for sustainable ICT projects in the developing world
}

\author{
Laura Hosman University of California, Berkeley, USA \\ Elizabeth Fife University of Southern California, USA
}

\begin{abstract}
Projects that bring information and communications technology (ICT) to the developing world - and especially to rural areas - have the potential to empower the disenfranchised, foster economic opportunity, and narrow the digital divide that threatens to widen global disparity between the haves and the have-nots. However, given the remarkable growth of such undertakings around the world, there has been little corresponding effort made to address the vital issues of longterm project sustainability and the diverse motivations and incentives facing the actors involved. As a result, these projects continue to be implemented sporadically and in a piecemeal fashion, which in turn hinders our ability to define success and recommend best practices for implementing and/or scaling them. Through an analysis of public-private partnerships (PPPs), the prevailing vehicle for project implementation today, the article addresses the issue of sustainability through partnerships, and also asserts that developing world technology recipients must be considered as stakeholders, as they hold the key to project sustainability. Following an overview of both theory and the current state of ICT-related development projects, the article provides a case study of a Sri Lankan-based pilot project involving multiple stakeholders. This case reveals important success factors that can be applied to future developing world ICT projects.
\end{abstract}

\section{Introduction}

The level of interest and investment in projects that bring information and communications technology (ICT) to the developing world has skyrocketed in recent years. This trend reflects the high and ever-increasing expectations placed on ICT in terms of quality of life improvement, empowerment and economic development for the affected communities. A better understanding of the key components of successful projects remains elusive, however. Such projects have not yet been examined in the literature (London and Hart 2004), and are undertaken in an uncoordinated, piecemeal fashion. This lack of coordinated, well-planned efforts hinders our ability to gauge benefits and outcomes and, even, to define success.

Numerous multinational firms, particularly in the ICT sector, have begun to recognise the economic potential represented by the four billion people occupying the 'bottom of the pyramid' (Prahalad 2004) in the developing world. They are initiating ambitious projects aimed at serving 
and developing these markets. Yet, given the high failure rate for such ventures and the absence of a business model proven to function in such uncharted territory, the demand for an enumeration of best practices is extremely high.

Public-private partnerships (PPPs) - agreements between privatesector, for-profit businesses and developing country public sector actors are currently held in extremely high esteem by those seeking ICT solutions to development challenges. These partnerships enjoy broad support and are promoted by governments, international organisations, non-governmental organisations (NGOs) and private firms alike. In fact, the United Nations Millennium Declaration specifically recommends the creation of PPPs to 'ensure that the benefits of new technologies, especially information and communications technologies . . . are available to all' (Weigel and Waldburger 2004:XV).

Because there are numerous potential benefits - increases in efficiency, financial resources, human capital, technology, market access, and technical expertise, as well as the ability to scale projects - when public and private actors join forces, these partnerships are coming to be seen as the most efficient method for bridging the digital divide. Whether the reality matches the potential and whether the pilot projects become sustainable and scalable is, however, another issue deserving analysis.

The article addresses the following questions: if the success of such projects is judged by long-term sustainability, how can this best be pursued? If the long-term success of a project is determined by whether ICT is adopted by the recipients, and whether their quality of life improves as a result, how can projects be designed with these as their ultimate goals?

Two paradigm-shifting requisites for doing business with the poor of the developing world are identified: the first is to plan for the long-term sustainability of projects through focusing on the wants, needs, and characteristics of the local communities, and to consider the residents as project stakeholders. The second is to form partnerships to carry out the projects.

In this article we begin with a discussion of the topic's importance, as well as a review of relevant literature. Next, the methodology is presented. Following that, we highlight the need for a better understanding of what contributes to successful projects by discussing the (paucity of) existing theory, to which we both add and critique. We follow this section with a case study, based in Sri Lanka. The case reveals important success factors that can be applied to future digital divide projects. We conclude with an overview of best practices and a call for future research.

\section{ICT for development: the current debate}

Some critics question the value of ICT to address the needs of the developing world - why not focus on a nutritional, educational, opportunities, or health care divide? This is the essence of the 'bread vs. broadband' debate. Given the more basic needs not being met in poor countries, how much of the government's limited funds (or international aid efforts, for that matter) should be devoted to technology issues?

While acknowledging the above query, we believe the bread vs. broadband dichotomy to be a false one: basic needs and the utilisation of 
technology should not be thought of as an either/or, which-comes-first proposition. They are not mutually exclusive. ICT may correctly be thought of as an enabling tool: it is the practical application of knowledge in the areas of information and communications. From a long-term historical perspective, economic development has been a story of technological change - both invention and application. To claim that development without technology is possible is to turn a blind eye to reality. Therefore, perhaps the more appropriate question in this debate is: why not utilise technology to effect change, if the status quo is one in which basic needs are not being met?

Others question whether partnerships involving the private sector are the best way for public entities in the developing world to advance with infrastructural endeavours or to provide public goods. Our response to this concern is that such projects often do not advance at all when left to developing country governments' own resources and initiatives. For the public partner, PPPs offer attractive advantages, such as increased private investment, technological experience and expertise, risk-sharing, and a potential decrease in governmentally subsidised programs. A further argument for PPPs on economic grounds concerns the benefits associated with a liberalising of regulations and markets (at least in the telecom sector), increased exposure to technology and more efficient ways of doing business, and a stronger incentive to adhere to the policies of fiscal discipline required to do business with global companies. An additional motivation for governments, and certainly for the recipients of the technology, is the valueadding potential of ICT, not just in terms of economic growth, but also through improvement of social and political capital.

Possible negative outcomes for governments include asymmetries of power and information, and political and financial risks in the event of failed projects, with the possibility of private partners pulling up stakes and departing in the case of an unsuccessful project. Even so, citizens' increase in demands for governmental services, paired with stagnant government revenues, points to the likelihood of more PPPs being created in the future, particularly in developing countries.

Of course, for a given ICT project to be successful, locally appropriate technology must be deployed. 'Locally appropriate' in this case refers both to the stated wants and needs of the technology recipients as well as to what is possible given the physical, geographical, and/or infrastructural reality on the ground. Yet, once again, technology, through both invention and application, has rendered some traditional stumbling blocks to ICT implementation obsolete. An example will illustrate the concept: in a recent USAID Last Mile Initiative in rural Vietnam (see Fife and Hosman 2007), the project's emphasis was on enabling voice communications, as this was the capability the local residents expressed the most desire to have.

The projects made use of three notable technological innovations to lower costs and increase effectiveness for the ICT recipients: Voice over Internet Protocol (VoIP), Satellite and/or WiMAX technology, and solar power. VoIP represents the least expensive method of voice communication known today. The WiMAX technology enabled the network to be available across a larger geographical area than was previously possible, and 
avoided the prohibitively expensive costs of laying telephone lines. Solar powered modems and Wi-Fi towers obviated the need for a reliable electricity source (solar mobile phone chargers are also available). These technological innovations effectively minimised both short-term and long-term costs by enabling both voice communications - the locally desired capability and Internet service, for which demand may increase over time, with a single technology deployment. They also found a way around what had previously been considered a necessity: a reliable source of electricity.

When projects are well thought out, technologically appropriate, and designed with long-term sustainability and the empowerment of the localities in mind, they can bring about real socio-economic benefit in the basic needs areas mentioned above.

We argue that this subject is worthy of academic analysis because the phenomenon is already taking place: numerous Western-based technology multinationals have already launched ambitious development-related agendas and have formed PPPs to do so. And it is a cause for concern that, to date, there has been a lack of systematic, unbiased research guiding and/or assessing the significant and growing amount of activity in this area.

\section{Methodology}

This research employs a qualitative, case study methodology, which is particularly relevant for researchers examining strategies in emerging economies. In addition, the case study is the most appropriate method for studying the 'many variables-small $N$ ' type of subject presented here (Lijphart 1971). The case study is best employed when there are a limited number of cases for analysis, as it allows the researcher to examine the study intensively.

One additional strength of the case study methodology is the contribution it can make to theory building, and to best practices identification. We adopt Gerring's (2004: 342) definition of a case study as 'an intensive study of a single unit for the purpose of understanding a larger class of similar units'. The case under consideration will be utilised to identify best practices. These findings will also be informed by existing theory and by the experiences of firms doing business in emerging economies.

Of equal necessity, however, is the ability to test the applicability of findings across similar cases. Though such testing will remain a challenge for future research, it is the authors' intention to apply these findings across future cases to test their applicability. Relevant cases do exist, and given the fervent and growing interest in bridging the digital divide, we are confident the number of such cases will grow.

The case presented here was chosen because it possesses many characteristics that will be addressed in the article. The Sri Lanka project brings broadband ICT access to rural areas of this developing state. It is a pilot project undertaken with an eye to potential scaling and expansion on a nation-wide and even international basis. It will encourage local entrepreneurship and offer a variety of value-adding training courses to address the socio-economic desires of the local technology recipients. Additionally, it features a PPP involving numerous partners, with the main coordinator being a small, US-based firm. 
The case will be compared and contrasted with existing theory and an overview of MNC involvement at the bottom of the pyramid as well as the discussion of PPP presented in the article. It will also serve to inform the best practices section.

\section{Theories, concepts and research}

The topic of ICT for development comprises a number of academic subject and interest areas, including, but not limited to, economics, business (ethics) studies, information systems, technology studies, sociology, politics, and development. Accordingly, it may not be surprising that there is no agreed-upon theoretical framework for analysis, nor any main repository for acquired knowledge or best-practices. As a result, our brief overview draws from a wide range of sources.

A number of academic studies from the field of economics have researched the role that ICT can play to fight poverty and catalyse socio-economic development and growth. There have been a number of macro-level studies demonstrating the positive impact of ICT on economic growth and development (see, e.g., Roller and Waverman 2001; Cronin et al. 1993). To date, however, these studies have utilised data from the developed world. There is still a need to replicate these studies using data from the developing world - although at this time, such data remains prohibitively limited.

In the literature of theoretical economics, endogenous growth theory (or new-growth theory) stipulates that it is technology and human capital, when endogenously present, that contribute to continuous economic growth and play an essential role in a country's development (Easterly et al. 1994; Barro 1997). Logically, workers who are better-educated, betterfed, healthier and technologically capable can produce more than those who are illiterate, hungry, unhealthy and unskilled.

Robert Barro's (1991) statistical analysis of the difference in growth rates across a large number of countries reveals that a high initial level of human capital has a significant positive effect on growth. This growth, in turn, further raises the level of human capital, and so forth, thus forming a virtuous circle. We can predict that ICT penetration - the ability to use technology to increase efficacy and efficiency - would have the same reinforcing effect.

Other research has considered the social impact of telecommunications technology in the developing world. De Silva and Zainudeen (2007: 2) rightly point out that such 'social' use of ICT is not to be considered frivolous - the ability of family members to stay in touch with one another contributes to a better quality of life.

Yet research at both the theoretical and micro level is still notably lacking (London and Hart 2004; de Silva and Zainudeen 2007). This article contributes to the research agenda in both areas, providing an analysis and critique of current theories regarding the use of ICT for development purposes, with a particular focus on multinational ICT corporations, to do so.

The article contributes to the case-study/empirical evidence body of literature, presenting an illustrative ICT-for-development project taking place in Sri Lanka that features a multi-stakeholder PPP. Ideally, such partnerships 
are thought to create synergistic results by combining the expertise and resources of the private partner with the administrative and political power of the governmental partner.

The partners in such initiatives may come to these projects with divergent motivations - profit on the one hand and the provision of public services on the other - but at the end of the day, the interests of the partners that are symbiotic can, and indeed should, be aligned to ensure successful long-term projects. Still, not a great deal is known about the PPP business model; this helps to explain the large number of unsuccessful initiatives (Angerer and Hammerschmid 2005). The fact that many failed cases go unreported does not help the learning process, either.

We argue that when these types of ventures are well thought out and designed with the empowerment of localities as their priority they can bring about long-term socio-economic benefits in numerous areas. In the field of ICT, broadband connectivity can enable local small business entrepreneurship, provide crop pricing information in advance of sales, increase knowledge of successful farming techniques and of labour opportunities and going wage-rates, and allow for the institution of tele-education and tele-health. These are just a few of the value-adding benefits communications connectivity can provide, but their potential is more likely to be realised when projects are designed with sustainability and local needs and desires in mind. This primary focus has been missing from numerous digital divide projects and analyses to date.

Since there is no theoretical framework that focuses specifically on partnerships of this kind (Stewart and Gray 2006), the article presents a hybrid overview of stakeholder theory and policy networks theory, as these are the two most relevant frameworks for understanding the case under consideration.

The concept of a 'stakeholder' in academic theory finds widest parlance, and indeed has its origins, in business (ethics) and management literature, although economists, political scientists and development scholars are increasingly making use of it. At base, it differentiates its own theory of the firm from neoclassical, behavioural, transaction cost, or cooperative game theory by claiming that there are other stakeholders besides management, owners, and shareholders affecting and being affected by the firm's business decisions, and that these other stakeholders' interests (should) matter.

In terms of the case study, the stakeholder concept has been essential to the project's implementation. Synergy Strategies Group (SSG), the firm charged with implementing the project, and USAID, a co-funder of the project, took into consideration the desires of the local residents in the cities where the project's telecentres were to be located by asking them whether they would be interested in telecentre services, and if so, which ones. In doing so, it treated them as stakeholders.

Additionally, in laying out a business plan for the project, SSG identified numerous other stakeholders, including local and international firms necessary to the project's success. The firms identified represented the following sectors: banking, hardware and software technology, service and training support, a telecom provider and an NGO. However, rather than 
simply considering these parties as stakeholders, SSG took a step further and asked each to become contractual partners in the project with stakes in the long-term outcome. This degree of partnering is the unique and groundbreaking aspect of the case at hand and the reason we now turn to the concept of partnership.

As mentioned above, the concept of partnership has come into favour among many organisations that promote development, but a theoretical framework for understanding how they work or what a partnership business model should look like has not yet been developed. The concept of partnership has its origins - and finds its widest usage - among environmental and development scholars. For these scholars, the notion of sustainability has been a key concept since the 1970s (Stewart and Gray 2006), while other fields of study have rather recently adopted the notion.

Partnership, as it is used here, describes a business relationship between individuals (or firms) who (which) unite in a profit-making enterprise. In 2002, the United Nations held a World Summit on Sustainable Development where a number of guiding principles for sustainable development partnerships were put forward (Kara and Quarless 2002). The main concept underlying any partnership is that it is established to achieve goals that could not be realised by a single party acting alone. The following principles were also enumerated:

- Partnerships are based on mutual respect and the shared responsibility of those involved.

- Each partner's role, as well as its objectives, intended outcomes, and benefits, should be clearly defined and transparently reported on a regular basis.

- Partnerships should integrate the economic, social and environmental dimensions of sustainable development in their design and implementation and should be consistent with poverty reduction strategies where their implementation takes place.

- Partnerships should have a multi-stakeholder approach and involve a range of significant actors in a given area of work. They can be arranged among any combination of partners, including governments, regional groups, local authorities, NGOs, and those from the private sector. All partners should be involved from an early stage, so that the approach is genuinely participatory. Yet, as partnerships evolve, there should be an opportunity for additional partners to join on an equal basis.

- Partnerships should add value in terms of human development goals.

These principles can serve as valuable guidelines for future partnerships undertaken in the developing world; they will serve to inform our review of best practices in the case presented below.

\section{Doing business with the world's poor: models, theories and experiences}

As developed world markets for goods and services have matured, multinational corporations increasingly look to the developing world to find or create new high-growth markets for their products. Up until recently, 
these MNCs' business strategies generally could be characterised as replications of what had worked for them in developed markets: partnering with established local firms, retaining existing products, and focusing on the wealthy elites of developing world countries (London and Hart 2004). Although this strategy expanded MNCs' global reach, it proved limited in terms of increasing profitability, and, in fact, has contributed to widening the divide between the haves and the have-nots within these countries, leaving MNCs open to criticism of neo-imperialism.

Over the past few years, however, in large part due to the work of C.K. Prahalad (2004), there has been a growing recognition of a largely untapped potential market: the four billion people at the "bottom of the (economic) pyramid' (BOP). The acknowledgement of this segment of the population as a potential market represents an attitudinal shift on the part of large, western MNCs, which are now eager to expand their reach to include it.

However, given the large number of 'early mover' failed initiatives in recent years, there is also a growing comprehension that reaching this group and realising successful ventures will require a new business strategy - one heretofore not addressed in the literature or theory of emerging market business models. Thus, while reaching the bottom of the pyramid holds enormous opportunities, it also presents unique challenges requiring corresponding solutions. As a result, there is great demand on behalf of these corporations both to do business with the world's poor and to understand how best to do so.

In seeking to understand which factors will contribute to the success of BOP strategies, two salient points have emerged from the literature. The first is that the developing world often conducts business according to different rules and norms than those to which western firms are accustomed. In the absence of efficient, formal markets and the rule of law to uphold property rights, social norms and informal contracts form the structure for transactions and the respect of outcomes (London and Hart 2004).

For example, in the widely cited Grameen Bank (and Grameen Phone) program, the success of its micro-lending initiative was dependent on social pressure: if one person defaulted on a loan, no others in his or her peer group would be eligible for a future loan. It is doubtful that this particular incentive model would work well in a (western) society that values the individual above the community, nor in one in which the individual or the business has recourse to reliable legal means by which to recover property. As a result of this fundamental difference in societal expectations, western-based firms need to discover a fundamentally different way to conduct business - in precisely the way that developing country residents cultivated their own methods for getting things accomplished and having outcomes respected, given a lack of law and order and transparent, functioning markets.

This will require corporations to reinvent their current 'competitive advantages', particularly in terms of branding, contract enforcement, and patents (London and Hart 2004). But in addition to re-thinking the ways business is conducted, there must also be a shift in mentality in order to understand the importance of society to those at the bottom of the 
pyramid. This point is two-pronged: since society is paramount to these groups, social issues must be considered even in economic endeavours. In essence, Milton Friedman's (1970) take on the requirements of business 'The social responsibility of business is to increase its profits' - may not fly in the developing world, where the emphasis is on society.

MNCs interested in doing business with BOP residents may be wise to consider projects that add societal as well as economic value. In practical terms, this also means that a bottom-up rather than a top-down approach will lead to greater chance of project success. By understanding what the technology recipients in the developing world truly want and need - what their pressure and pain points are, as well as what their unique societal concerns may be - the projects proposed are more likely to address real existing needs and, as such, stand a much better chance of succeeding than those thought up by a research and development team in a far-off locale with the aim of selling a product that their company already makes.

The second major change required of western companies seeking to penetrate the BOP market is that an entirely new paradigm for doing business must be adopted: one of partnering. This may include contracting with local businesses and entrepreneurs, civil society groups, non-government organisations, intergovernmental organisations, the national government, the local government, and/or ministries and is a structure that is likely far less efficient than that to which the multinational is accustomed, but one that is necessary if they are to understand and be accepted by their 'target audience'. The partners in a given project must be determined by the particular project under consideration, and may not be seen as a one-size-fits-all proposition.

PPPs between ICT companies and the governments of developing nations are increasingly formed with the support of international organisations like USAID, the World Bank, and the UN. In 2002, UN SecretaryGeneral Kofi Annan challenged the technology corporations of Silicon Valley to do more in the public/private partnership arena; to unleash their creative energies to bring wireless technologies to the developing world and narrow the gap between technological 'haves' and 'have-nots' (Annan 2004). Accordingly, ambitious projects aimed at bridging the digital divide have been announced by such companies as Microsoft, AMD, Intel, and Cisco. Substantial investments have been proposed and projects are already underway. Microprocessor manufacturer AMD, for example, is in the second year of its $50 \times 15$ initiative, which seeks to provide Internet access to half of the world's population by 2015 (about 15\% of the world's population presently has Internet access).

This emphasis on addressing basic needs represents a paradigm shift: in the past, basic improvements in daily life - when they took place at all were assumed to be a by-product of multinational involvement in emerging markets. The enthusiasm of governments and non-governmental organisations to support private enterprise-led projects also marks a significant change in perspective regarding corporate involvement in growth plans.

Yet, despite the numerous potential benefits and an increase in the number of PPPs around the globe, the academic community reports mixed 
results for such undertakings. There are numerous cases of failed PPPs. These partnerships are often misunderstood and work well only under certain conditions. Because of this, a good deal of organisational and instructional literature has been created with the goal of enumerating and promoting best practices to ensure successful joint ventures (see, e.g. United Nations Foundation 2003).

Complicating matters has been the fact that corporations have been both sending and receiving mixed signals regarding their motivations for becoming involved in such endeavours. AMD's website announces its World Ahead Program intentions. 'Making a profit and making the world a better place do not have to be mutually exclusive goals.' Yet even the United Nations recognises that private sector companies are not philanthropic organisations and that PPPs are formed out of self-interest. Firms' core objective remains profit.

Even so, corporations take advantage of the positive externalities associated with the perceived philanthropic nature of these projects and utilise them as a marketing tool on their websites. They also report immediate tangible benefits, such as improved morale among their own workforce and the creation of a positive company image at home and abroad.

The literature addressing this topic has been similarly divided in its recommendations and findings in terms of whether corporations should act out of a sense of social responsibility or merely pursue profits. Often, the exhortation for corporations to act out of both motivations appears, separately, within the same article (Prahalad and Hammond 2004; London and Hart 2004). This bifurcated approach stems from the complicated reality in which the world's poor desire an opportunity for (socio-)economic growth that is currently not available to them, yet the large corporations that may provide them this potential seemingly need convincing that the poor comprise an attractive market that is worth their economic investment and risk.

Although at face value this may seem a benign argument, there is, in fact, at its very base a conflicting logic that will be difficult for MNCs to overcome. On the one hand, many authors point out that, due to the important notion of society among the world's poor and their expectations for what may be called a multifarious concept of development, an integrated approach to economic growth, poverty alleviation, and environmental sensibility must be respected in any development efforts (see, e.g. Sen 1999; Stiglitz 2002; World Bank 2001). These authors want the corporations to know this and change their ways of doing business to ensure that social value will be created for the people who are the target of their projects. In this way the bias against corporations as being 'foreign' can be overcome.

On the other hand, but in a similar vein, corporations are warned against either expecting that developing country citizens will 'evolve' eventually in their ways to resemble a western-style market economy or pattern of development, or of trying to force them into said style. In other words, 'MNC managers and academics must move beyond the "imperialist mindset" that everyone must want to look and act like Westerners' (London and Hart 2004: 354, citing Prahalad and Lieberthal 1998; see also Arnold and Quelch 1998). 
If scholarly recommendations for western corporations (to best do business with those at the bottom of the pyramid) are to stop behaving like western corporations in both their actions and expectations, what does this say about the appropriateness of these MNCs as the best or even most likely candidates for the job? If the goal is not to make over the developing world in the west's image, then perhaps encouraging even greater global reach and domination by these corporations is not the best solution available.

If the goal is truly to respect the BOP's desires to grow in a holistic socio-economic way, then, at the very least, we argue that small firms - as well as local, indigenous companies - may be better positioned to understand and create opportunities for the BOP.

This is not to argue that there should not or cannot be a valuable role for western MNCs in the development picture. Our case study provides evidence of such partnering that is productive and fruitful. Yet we still intend to question the notion that world-dominant MNCs should be relied upon to lead the charge to global development, and argue that small and local companies can be effective as well.

In the end, however, whether the instigating partner is large or small, the focus must still remain on the recipients of local technology and on formulating effective, sustainable partnerships. For most partners, sustainability will translate into the need for profitability or a return on investment. The local residents must be treated as stakeholders as well; when this means that they will also have a stake in the financial outcome and/or will be able to see an improvement in their quality of life, the prospects for a given project's success will improve.

\section{Case study: EasySeva in Sri Lanka}

The case presented here serves to illustrate a number of the best practice characteristics discussed throughout the article. As such, it contributes to the empirical evidence for addressing our research questions of how best to formulate sustainable, scalable partnership projects aimed at bringing ICT to rural areas of the developing world.

EasySeva (or Easy Service in the local languages) is the name given to a for-profit franchise service center project to bring affordable broadband wireless telecommunications and Internet technology to rural areas of Sri Lanka. It is a PPP with multiple local and international partners from numerous sectors of relevant industries. The aim of the EasySeva project is to empower the rural communities to avail themselves of ICT in order to improve their quality of life, as well as their economic status (Synergy Strategies Group [SSG] 2007).

The EasySeva business strategy is built around a franchising model. Local entrepreneurs - generally those already employed in mobile phone 'top-up' shops or in dial-up cyber cafes - are identified (by the local phone companies through which they are employed), interviewed, and recruited to establish village-level kiosk franchises that provide Internet and telephone access to the local population. Through EasySeva the potential franchisees are offered the opportunity to start a business by purchasing a low-priced kiosk package, or 'Center/Franchise-in-a-box', which consists of four reconditioned personal computers (PCs) with a licensed suite of 
1. WiMAX is defined as Worldwide Interoperability for Microwave Access. The difference between Wi-Fi and Wi-Max is that the WiMAX specification provides symmetrical bandwidth over many kilometers and range with stronger encryption and typically less interference. Wi-Fi has shorter range (approximately 10's of meters,) weaker encryption and suffers from interference, as in metropolitan areas where there are many users, or when there are obstacles to its line-of-sight.

2. HSDPA is defined as High-Speed Downlink Packet or Protocol Access, which allows networks based on Universal Mobile Telecommunications System (UMTS) to have higher data transfer speeds and capacity.
Microsoft Office products, an all-in-one printer/copier/fax machine, broadband connection via Dialog Telekom (which is either through WiMAX ${ }^{1}$ or HSDPA $^{2}$ technology), and one or two Voice over Internet Protocol (VoIP) enabled telephones (SSG 2007).

There are two major technological advances that have enabled this project's realisation and hold promise for revolutionising similar ICT undertakings across the developing world: wireless broadband and VoIP. These technologies are both revolutionary and enabling in a number of ways. Utilising wireless broadband means that the expense of laying fixedline wires or cables is avoided, bringing cost savings for all parties involved. WiMAX and HSDPA are also relevant technological advances: they increase the distance that modems can supply an Internet connection, which translates into cost savings.

VoIP technology is this project's primary voice communications application. As a result, both Internet connectivity and voice-related communications are enabled through a single technology deployment. This combined provision of Internet and voice in a single technology minimises both short-term and long-term costs, as VoIP over broadband presently represents the least-expensive method of communicating over long distances. It also addresses the issue of providing the service currently the most in-demand in the developing world - voice communications - while simultaneously providing Internet connectivity, for which demand may increase over time. Enabling residents of rural villages to make both local and long-distance calls at minimal cost provides increased efficiency in planning and communication; this can lead to economic growth.

In addition to the equipment, setup and connectivity, the franchise package also includes IT/business training, business plan support, a micro-loan and lease program, marketing support, and a 24/7 help desk. The majority of these items and services are provided directly by the numerous partners in the EasySeva project, which benefits from economy of scale and buying in bulk: it is able to provide technology, support and prices/rates well below those which any single operator, entrepreneur, or company could negotiate by itself. Additionally, the franchisee's required capital outlay (obtained through a start-up cost loan) reduces the up-front capital outlay burden for the main project partner, Synergy Strategies Group (SSG 2007).

While EasySeva provides kiosk owners with training, support, technical assistance, and access to financial assistance they otherwise would not have, in the end, the local franchise owners themselves are responsible for generating the income and profit to pay back their initial loan in a timely fashion (30 months). In other words, they are responsible for putting into practice the marketing strategies they are provided as part of their assistance, and for developing additional product and service offerings of their own. This is intended to challenge and stimulate the creative, entrepreneurial spirit.

At the service centre level, EasySeva provides extremely low rates for Sri Lankans to call relatives both in neighbouring villages as well as those far away. This is a valuable service, as the Sri Lankan expatriate workforce is extremely large. While estimates vary, in 1999 the Central Bank 
of Sri Lanka estimated that there were over 788 million expatriate workers, 90 per cent of whom are employed in the Middle East (Central Bank 1999; this statistic is no longer officially reported). Given the high rate of depression and even suicide among these workers (Toumi 2007), affordable overseas communication may truly be said to provide a 'lifeline' between loved ones.

EasySeva service centre franchisees also have the capacity to provide computer training services in the local languages (Tamil and Sinhalese) in order to make Internet access an effective development tool. Local townspeople were surveyed prior to the commencement of the project and initial feedback evinced community members' interest for taking ICT training courses in areas such as English as a second language (ESL), agricultural techniques, and so forth.

Since the Sri Lankan literacy rate in the local languages is 91 per cent, such Internet training programs are a locally appropriate technology application. Relevant local content will generate usage and additional revenue sources for the telecentres and franchisees, as well as significant socio-economic benefits for local users. The high literacy rate within the state also bodes well for Internet uptake - and adoption in general - as many of the more advanced technology applications, such as email and information gathering, require the ability to read and write. In this respect, Sri Lankans are better poised to realise a wide range of ICT-related benefits than many others in developing countries, and the expectations of this project regarding their abilities for and interests in taking computer training courses appear to be in line with the reality of the situation.

In addition to the above, in the near future, EasySeva customers will be able to apply for loans, make payments, and receive remittances in the centres. They will also be able to receive remote diagnoses from regional or national hospital doctors and nurses, which will improve local health conditions, as well as save patrons the time and travel costs of journeys to distant hospitals. EasySeva has a built in network for franchisees to share best practices and lessons learned that will add value as the number of franchises expands (SSG 2007).

The implementing partner of the EasySeva project is Synergy Strategies Group (SSG), a small, Vermont-based American firm. In the summer of 2006, SSG beat out a considerable number of established competitors for a USAID-sponsored Last Mile Initiative grant.

USAID's Last Mile Initiative (LMI) is its global program, launched in 2003 , to bring modern telecommunications infrastructure to farmers and small businesses in traditionally underserved rural areas. In doing so, it has been funding a number of country-specific ICT projects that make use of new, creative, and promising approaches for expanding telecommunications access.

One of the unique aspects of USAID's mission for such projects is that LMI programs are designed to be self-sustainable and subsidisation-free once they are up and running. USAID promotes this sustainability: it generally has an end-date for its participation in these projects, after which it departs, its funding stops, and the remaining partners fully take over the project. 
In the Sri Lanka Last Mile Initiative, USAID stipulated a number of project requirements with an eye to promoting long-term sustainability. Among these was 2-to-1 matching of project funds, wherein for every dollar provided by USAID the private sector partner had to match it with $\$ 0.50$ - with either its own or partner funds. To promote project scalability, USAID required a minimum of 20 centers to be fully operational within one year of the project award date, to ensure a 'proof of concept' for scalability. In addition, USAID encouraged and facilitated SSG's forming of alliances with both public and private sector partners.

At the end of September, 2006, SSG was awarded the contract and began implementation, which involved partnering with numerous organisations. From the beginning, SSG has viewed this project as a business development opportunity. Yet, rather than seeking to maximise profit off of the initial contract's realisation, as has been the case for USAID contractees traditionally, SSG will be utilising these funds as seed money - or venture capital - to fund, eventually, the opening of hundreds of EasySeva centres across the nation, and even internationally. Not only does this provide SSG a true long-term stake in the project, it also creates the incentives for contracted partners to realise profitability as well, promoting desire for continued participation in the project's expansion.

All of these characteristics contribute to the potential for the project's long-term sustainability. This performance-based contract model marks a shift on the part of USAID, which now recognises that correct incentives should be in place for aid-based funding to be effective; a project is more likely to be a success once all parties have a (financial) stake in the outcome. In fact, such incentivising represents a radical departure for USAID: traditionally, US firms merely extracted aid fees from the initial implementation of a project, and had little-to-no interest in the impact or sustainability of the project after the funding dried up.

The partners involved in the EasySeva project include public, private, local and international firms dealing in hardware, software, finance, technology and services provision. In addition to SSG and USAID, the partners include:

- Dialog Telekom, the largest mobile phone operator in Sri Lanka, providing internet connectivity and support, infrastructure, and technical expertise, and will ensure that regulatory requirements are met. It is also committing a project team of engineers and project managers to support the undertaking.

- InfoShare, a Sri Lankan NGO that will provide training and content support.

- Lanka Orix Leasing Company, providing leasing and financial support for franchisees to enable their purchase of the requisite hardware.

- National Development Bank of Sri Lanka, which has provided franchisees with working capital financing support (\$40,000 to date).

- Qualcomm, a global wireless communications company, which is providing both funding and the permission to use its HSDPA technology.

- Microsoft, a global computer technology corporation, has provided training materials and workshops on IT use (through their Unlimited Potential program, run in partnership with InfoShare). 
Synergy Strategies Group registered EasySeva, the franchisor, as a Sri Lankan Private company in early 2007. The company has exceeded the stipulated requirements of the LMI contract, opening 25 service centres by the August, 2007 deadline. The company plans to open 400-500 centres within Sri Lanka over the next 3-4 years, and an additional 1,000 centres around the South Asian region in the future. In order to make this a reality, they will need to attract sufficient private financing, which, in this case, means that the current partners must realise a sufficient profit to remain involved and, possibly, to expand their involvement as the project is scaled (SSG 2007).

\section{Success factors}

It may be too soon to comment on the long-term outcome of this case for the communities involved; whether the technology has been adopted and used in training courses, for loans and health-related matters, and so forth, and whether it has led to economic activity and growth. Even so, the project has been deemed successful on several fronts. It provides a groundbreaking example of partnering in line with a number of the guiding principles for partnerships.

First, the project took advantage of the intersection of common interests by the parties involved. SSG identified stakeholders, and invited them to become partners. All partners had a long-term stake in the project, driving both their participation and motivation.

As for the physical project, the PPP contract made clear that resources were not handouts but were provided in a collaborative-supportive approach which was based on the agreed-upon plan. Treating PPPs like the business ventures that they are gives parties incentive to stay involved, while the diversity of the parties forces participants to be flexible in their interactions.

In fact, until recently, community telecentres have suffered from a high failure rate for a number of reasons. Such projects have traditionally been initiated by NGOs with development assistance or government funds, but have not been treated as for-profit business ventures with long-term sustainability incentives in place. They often did not meet local needs, failed to provide local content or relevant training opportunities, and were not able to take advantage of the advanced technologies currently available (wireless broadband and VoIP) that have fundamentally altered the economic dynamic of rural connectivity. Lastly, with a lack of partners participating in such projects, they were not able to buy in bulk to bring down prices or negotiate for lower rates, nor were they able to share investment costs, or spread risk among partners, and thus they involved a heavy upfront investment by the donor organisation.

The EasySeva project has turned the former model on its head, reversing virtually all of the factors that contributed to the previous model's failure. Numerous partners were involved, ranging from local to international actors, from all sectors relevant to the successful rollout of the project. The partnership had clear objectives, transparent agreements, and measurable targets and timeframes. The partners were treated as equals, and were involved from the initial stages of the project, with room for future partners to become involved as the pilot is scaled. 
Finally, the local residents have been treated as stakeholders at all stages of this project. Targeted community members were consulted before the project began, to determine whether such a project would meet a desire or need. When the response was positive, the project moved forward. EasySeva provides the opportunity for economic benefit to participants, as well as the possibility to enhance the quality of their lives.

\section{The nexus: success factors that matter}

Re-shifting the focus to the bigger picture, several success factors have been identified for integrating ICT services into a community, both in the literature and in our case study. One of these factors is starting out small with a pilot project that can demonstrate scalability, whether the project is a partnership between top levels of government and a large multinational corporation or between multiple partners and spearheaded by a small firm. Modest efforts that are in line with local realities and are appropriate to local socio-economic conditions - as was the case in the EasySeva project - are more likely to be adopted by the local residents. Smaller projects also have more flexibility for changing conditions. There can be large returns from low-cost projects.

Services that are seen to be useful, and demonstrate their utility quickly, will be used in everyday life; this encourages further adoption. Buy-in by citizens is much more likely if services demonstrate an improvement over the status quo. Unexpected benefits can occur upon adoption of technology, and creativity may be unleashed when the entrepreneurial spirit is promoted.

The presence of a third party intermediary, here USAID, was also found to be extremely useful at identifying and bringing together potential partners. This actor's focus - not on profits, but on crafting a sustainable project in the long-term - was particularly fruitful during the contract-formulation stage, when each player involved was given a long-term (financial) stake in EasySeva's outcome. Forming a solid contract tends to benefit all players throughout the life of the project. In this case, the groundbreaking contract took into consideration the long-term sustainability of the project by giving all partners an incentive, not just for a successful project, but for one that would ultimately be scaled, as well.

Finally, starting from the bottom-up and not the top-down helps reveal the wants and needs of the people who will ultimately determine whether any project is successful in the short- and long term. Locally relevant programs can only be designed with an in-depth knowledge of the potential technology recipients; this includes such diverse considerations as the understanding of societal norms, literacy levels, employment options, weather-related concerns, factional/religious/ethnic sensitivities, government openness or repression, and so forth. The list - which could continue without end - serves to illustrate that digital divide projects can never be considered a one-size-fits-all proposition. The local stakeholders must be the central focus of any and all such undertakings.

The digital divide was once considered merely an issue of access. A more meaningful distinction currently understood involves the disparity in real access, defined in terms of both physical access and usability, or 
adoption into one's daily life (UN 2004: 8). Developing a beneficial 'culture of use' is most likely to take place when success factors are present: services are visible, frequently used, context specific, have a human face, and meet tangible needs. ICT investments in the developing world will continue to grow in the coming years. Thus, there is great opportunity for careful investigation into how these resources can best be used to fight poverty, empower and promote development.

\section{Conclusion}

While progress has been made in the gathering of information about ICTrelated PPPs in the developing world, much remains to be done in terms of the accumulation of empirical evidence, building of theories, and identification of best practices. The multitude of related projects currently underway provides an unprecedented opportunity to learn about how social and economic change can be furthered through technological advance. These lessons may be applicable in contexts other than that of information and communication technology, but the expectations placed on this particular realm are high, given its ability to drive and enable efficiency and development in all of the areas to which it is applied.

Serving the needs of emerging markets and those at the bottom of the pyramid offers many challenges and opportunities to the private sector. Developing country governments, and other organisations acting alone, have not been able to mount an effort comprehensive enough to eradicate poverty in the lowest tiers of the economic pyramid (Hart 2005). PPPs thus offer great opportunities for technological advancement in the developing world. Still, there is a need for careful study of these initiatives, in order to ensure successful projects and to encourage the use of ICTs to further human development.

\section{References}

Angerer, D.J. and Hammerschmid, G. (2005), 'Public Private Partnership between Euphoria and Disillusionment. Recent Experiences from Austria and Implications for Countries in Transformation,' Romanian Journal of Political Science, 5: 1, pp. 129-159.

Annan, K. (2002), 'Kofi Annan's Challenge to Silicon Valley,' 5 November 5, http://news.com.com/2010-1069-964507.html. Accessed 18 February 2007.

Arnold, D.J. and Quelch, J.A. (1998), 'New Strategies in Emerging Markets,' Sloan Management Review, 40: 1, pp. 7-20.

Barro, R.J. (1997), 'Economic Growth in a Cross-Section of Countries,' Quarterly Journal of Economics, 106, pp. 407-443.

- (1997), Determinants of Economic Growth, Cambridge: The MTT Press.

Central Bank of Sri Lanka (1999), Key Economic Indicators, Central Bank of Sri Lanka Printing Press.

Cronin, F.J., Colleran, E.K., Parker, E.B. and Dollery, B. (1993), 'Telecommunications Infrastructure Investment and Economic Development,' Telecommunications Policy, 17: 6, pp. 415-430.

De Silva, H. and Zainudeen, A. (2007), 'Teleuse on a Shoestring: Poverty Reduction through Telecom Access at the Bottom of the Pyramid,' March, LIRNEasia, www.lirneasia.net. Accessed 9 August 2007. 
Easterly, W., King, R., Levine, R. and Rebelo, S. (1994), 'Policy, Technology Adoption and Growth,' NBER Working Paper No. 4681, Cambridge: National Bureau of Economic Research.

Fife, E. and Hosman, L. (2007), 'Public Private Partnerships and the Prospects for Sustainable ICT Projects in the Developing World,' Journal of Business Systems Governance and Ethics, 2: 3.

Friedman, M. (1970), 'The Social Responsibility of Business Is to Increase its Profits,' The New York Times Magazine, 13 September.

Gerring, J. (2004), 'What is a Case Study and What Is it Good for?' American Political Science Review, 98: 2, pp. 341-354.

Hart, S. (2005), Capitalism at the Crossroads: the Unlimited Business Opportunities in Solving the World's Most Difficult Problems, Wharton School Publishing: New Jersey.

Kara, J. and Quarless, D. (2002), 'Guiding Principles for Partnerships for Sustainable Development ('type 2 outcomes') to be Elaborated by Interested Parties in the Context of the World Summit on Sustainable Development (WSSD),' Johannesburg Summit, 7 June 2002. http://www.isd.ca/wssd/ download\%20files/annex_partnership.pdf. Accessed 9 September 2007.

Lijphart, A. (1971), 'Comparative Politics and the Comparative Method,' The American Political Science Review, 65, pp. 682-693.

London, T. and Hart, S.L. (2004), 'Reinventing Strategies for Emerging Markets: Beyond the Transnational Model,' Journal of International Business Studies. 35, pp. 350-370.

Prahalad, C.K. (2004), The Fortune at the Bottom of the Pyramid, Wharton School Publishing, New Jersey.

Prahalad, C.K. and Hammond, A. (2002), 'What Works: Serving the Poor, Profitably: A Private Sector Strategy for Global Digital Opportunity,' World Resources Institute \& The Markle Foundation, http://pdf.wri.org/whatworks_ serving_profitably.pdf. Accessed 8 August 2007.

Prahalad, C.K. and Lieberthal, K. (1998), 'The End of Corporate Imperialism,' Harvard Business Review, 76: 4, pp. 68-79.

Roller, L. and Waverman, L. (2001), 'Telecommunications Infrastructure and Economic Development: a Simultaneous Approach,' The American Economic Review, 91: 4, pp. 909-923.

Runde, D. (2006), 'How to Make Development Partnerships Work,' OECD Observer, No. 255, May, pp. 29-31.

Sen, A. (1999), Development as Freedom, New York: Anchor Books.

Stewart, A. and Gray, T. (2006), "The Authenticity of "Type Two" Multistakeholder Partnerships for Water and Sanitation in Africa: When is a Stakeholder a Partner?,' Environmental Politics, 15: 3, pp. 362-378.

Stiglitz, J. (2002), Globalization and Its Discontents, New York: Norton \& Company.

Synergy Strategies Group (2007), 'Center-in-a-box: Broadband in rural Sri Lanka.' 26 June, http://www.synergystrategiesgroup.com/. Accessed 8 August 2007.

Toumi, H. (2007), "Expat Blues Fuel Suicide Rate," Gulf News, 10 August, http://archive.gulfnews.com/articles/07/08/11/10145589.html. Accessed 14 August 2007.

United Nations (2004), UN Global E-Government Readiness Report, 2004: Towards Access for Opportunity, Department of Economic and Social Affairs, Division for Public Administration and Development Management, New York. 
United Nations Foundation and World Economic Forum (2003), 'Public Private Partnerships: Meeting in the middle'. https://www.weforum.org/pdf/Initiatives/ GHI_2003_Meeting_in_the_middle.pdf. Accessed 18 February 2007.

Weigel, G. and Waldburger, D. (2004) (eds.), ICT4D: Connecting People for a Better World. Lessons, Innovations and Perpsectives of Information and Communication Technologies in Development, Swiss Agency for Development and Cooperation (SDC) and Global Knowledge Partnership (GKP), Berne, Switzerland.

World Bank (2001), World Development Report 2000/2001: Attacking Poverty, Oxford: Oxford University Press.

World Bank (2003), 'ICT for Development Contributing to the Millennium Development Goals: Lessons Learned from Seventeen InfoDev Projects,' Washington, D.C.: The World Bank.

\section{Suggested citation}

Hosman, L., \& Fife, E. (2008), 'Improving the prospects for sustainable ICT projects in the developing world', International Journal of Media and Cultural Politics 4: 1, pp. 51-69, doi: 10.1386/macp.4.1.51/1

\section{Contributor details}

Laura Hosman holds a Ph.D. in Political Economy and Public Policy from the University of Southern California (USC). She is currently a Ciriacy-Wantrup Postdoctoral Fellow at the University of California, Berkeley, and a Postdoctoral Researcher with the Center for Telecom Management through the Marshall School of Business at USC. Her work focuses on sustainable development issues, particularly in the areas of ICT and natural resources. Contact: Department of Environmental Science, Policy \& Management, 118 Giannini Hall, University of California, Berkeley, 94720, USA. Tel: 1 (510) 665-5612.

E-mail: hosman@berkeley.edu

Elizabeth Fife, Ph.D., is Principal Researcher at the Center for Telecom Management of the Marshall School of Business at the University of Southern California (USC). She also teaches technical communications in the Engineering Department at the USC. Her work focuses on the role for information and communications technology (ICT) in developing countries, particularly in terms of its potential effects on socio-cultural factors, human development, and economic growth. Contact: Marshall School of Business, University of Southern California, 444 South Flower Street, Suite 1000, Los Angeles, CA 90089, USA. Tel: 1 (213) 740-9347, Fax: 1 (213) 740-1602.

E-mail: fife@marshall.usc.edu 